\title{
Acute renal failure due to glomerulonephritis associated with staphylococcal infection
}

\author{
E. R. MAHER* $\dagger$ \\ B.Sc., M.R.C.P. \\ S. THIRU† \\ M.R.C.Path.

\begin{abstract}
Summary
Acute renal failure developed in a diabetic with staphylococcal arthritis and septicaemia in the absence of endocarditis. Renal biopsy showed proliferative glomerulonephritis and there was evidence of alternative pathway of complement activation. Renal function recovered following haemodialysis for 2 months. The association of glomerulonephritis with staphylococcal infection is reviewed.
\end{abstract}

\author{
D. V. HAMILTON* \\ M.A., M.R.C.P. \\ T. WHEATLEY* \\ M.A., M.R.C.P.
}

Departments of Nephrology* and Pathology $\dagger$, Addenbrooke's Hospital, Hills Road, Cambridge

KEY WORDS: proliferative glomerulonephritis, diabetes mellitus, septic arthritis, C3 nephritic factor.

\section{Introduction}

Acute renal failure may complicate severe bacterial infections, but it is not generally appreciated that this may be secondary to glomerulonephritis rather than acute tubular necrosis. Glomerulonephritis in staphylococcal infections of ventriculo-atrial shunts or endocarditis is well recognized (Black, Challacombe and Ockenden, 1965; Gutman et al., 1972), but has rarely been reported with other sites of infection.

\section{Case report}

A 45-year-old female with Type I diabetes mellitus for 15 years was admitted in ketoacidosis precoma with a pyrexia and a swollen elbow joint. Before admission there had been no evidence of diabetic nephropathy, retinopathy or neuropathy. Conventional therapy for diabetic ketoacidosis was supplemented with intravenous flucloxacillin and gentamicin. Staphylococcus aureus was isolated from cultures of blood and joint aspirate on day 2 .

On day 4 urinary output decreased and serum

†Present address: University College Hospital, Gower Street, London WC1E 6AJ. creatinine rose from $117 \mu \mathrm{mol} / 1$ to $164 \mu \mathrm{mol} / 1$ with a urinary osmolality of $308 \mathrm{osm} / 1$. Urine microscopy showed $12 \times 10^{6} / 1$ pus cells and more than $200 \times 10^{6} / 1$ red cells with granular casts present. The $24 \mathrm{hr}$ urinary protein excretion was $\mathbf{0 . 2} \mathrm{g}$. Serum creatinine continued to rise and oliguria progressed to anuria. Haemodialysis was started on day 10 and continued two to three times a week. Renal biopsy was performed on day 47 (see below). Haemodialysis was discontinued on day 84 , with a serum creatinine of $185 \mu \mathrm{mol} / 1$ and a creatinine clearance of $25 \mathrm{ml} / \mathrm{min}$. At no time were any cardiac murmurs detected.

\section{Immunology}

Immune complexes were measured by polyethylene glycol precipitation-complement consumption (Harkiss and Brown, 1979), complement and C3 nephritic factor using methods described by Brown and Hobart (1981).

On admission immune complexes were raised at 100\% (normal less than 24\%) and C3 levels were normal. Subsequently, immune complex levels declined but C3 levels fell to $32 \mathrm{mg} / \mathrm{dl}$ (normal 60-180 $\mathrm{mg} / \mathrm{dl}$ ) and C3 nephritic factor was detected. Levels of $\mathrm{C4}$ were normal and antinuclear factor was negative. By the time of discharge immune complex and complement levels were normal and $\mathrm{C} 3$ nephritic factor was undetectable.

\section{Renal pathology}

Light microscopy demonstrated a diffuse proliferative and exudative glomerulonephritis. Tubules, interstitium and vessels showed only mild non-specific changes. Direct immunofluorescence revealed intense diffuse granular staining of the glomerular basement membrane for $\mathrm{C} 3$ and focal staining for 
IgG. Staining for IgA, IgM, Clq and fibrinogen were negative. Electron microscopy demonstrated scattered electron dense hump-like deposits on the epithelial aspect of the glomerular basement membrane.

\section{Discussion}

Our patient is among the few reported in whom glomerulonephritis has been associated with staphylococcal infection in the absence of endocarditis. Early reports of infection-associated glomerulonephritis were mostly from post-mortem examinations (Nydahl and Hall, 1965). More recent reports have included patients with visceral abscesses and acute renal failure without endocarditis (including one patient with staphylococcal infection) in whom proliferative glomerulonephritis was found on renal biopsy (Beaufils et al., 1976). Less severe renal impairment associated with minor staphylococcal infections has also been reported (Spector et al., 1980). Infection associated glomerulonephritis is probably underdiagnosed. In acute renal failure acute tubular necrosis may be presumed if renal biopsy is not performed. In such cases haematuria may be a clue to glomerulonephritis, staphylococcal infections may play a role in the pathogenesis of some cases of primary glomerulonephritis (Sato, Nakazora and Ofuji, 1979).

The renal pathology is compatible with an immune-complex mediated pathogenesis and it is noteworthy that Staphylococcus aureus antigen has been identified by direct immunofluorescence within the glomeruli of a patient with staphylococcal endocarditis and glomerulonephritis (Pertschuk et al., 1976).

Hypocomplementaemia has been previously noted in infection associated glomerulonephritis, but according to Beaufils (1981) only in patients with endocarditis. It is therefore important to note that in our case hypocomplementaemia was found without evidence of endocarditis. Low C3 levels with normal levels of C4 suggests alternative pathway activation (Peters et al., 1972) and the C3 splitting activity detected appeared to be classical nephritic factor, i.e. an immunoconglutin binding to and stabilizing the $\mathrm{C} 3 \mathrm{bBb}$ complex causing activation and consumption of $\mathrm{C} 3$ without affecting the classical pathway C4-2 step. C3 nephritic factor is a IgG autoantibody and although most frequently found on Type II (dense deposit) mesangiocapillary glomerulonephritis, it has been detected in other forms of glomerulonephritis (Gwyn Williams et al., 1974).
Although recovery of renal function after haemodialysis for 2 weeks has been reported in a similar patient (Beaufils, 1981), recovery of renal function after haemodialysis for 2 months is not previously reported and emphasizes that the long-term prognosis can be good if infection is eradicated. In patients who have been rebiopsied after clinical recovery, regression of the histological changes has been observed (Beaufils et al., 1976).

In acute glomerulonephritis, evidence of infection should be sought as appropriate antibiotic therapy may improve the prognosis.

\section{Acknowledgments}

We wish to thank Dr O. M. Edwards and Dr D. B. Evans for permission to report this case, and Dr D. L. Brown for immunological studies.

\section{References}

BEAUFILS, M. (1981) Glomerular disease complicating abdominal sepsis. Kidney International, 19, 609.

Beaufils, M., Morel-Maroger, L., Sraer, J.D., Kanfer, A. \& RICHET, G. (1976) Acute renal failure of glomerular origin during visceral abscesses. New England Journal of Medicine, 295, 185.

Black, J.A., Challacombe, D.N. \& OCKenden, B.G. (1965) Nephrotic syndrome associated with bacteraemia after shunt operations for hydrocephalus. Lancet, ii, 921.

BROWN, D.L. \& HOBART, M.J. (1981) Complement and complement fixation. In: Techniques in Clinical Immunology. (Ed. R. A. Thompson), 2nd edn. Blackwell Scientific Publications, Oxford Gutman, R.A., Striker, G.E., Gilliland, B.C. \& Cutler, R.E (1972) The immune complex glomerulonephritis of bacteria endocarditis. Medicine, 51, 1.

Gwyn Williams, D., Peters, D.K., Fallows, J., Petrie, A:, KOURILSKY, O., MOREL-MAROgER, L. \& CAMERON, J.S. (1974) Studies of serum complement in the hypocomplementaemic nephritides. Clinical and Experimental Immunology, 18, 391.

HARKISS, G.D. \& BROWN, D.L. (1979) Detection of immune complexes by a new assay, the polyethylene glycol precipitationcomplement consumption test (PEG-CC). Clinical and Experimental Immunology, 36, 117.

NYDAHL, B.C. \& HALL, W.H. (1965) The treatment of staphylococcal infection with nafcillin with a discussion of staphylococca nephritis. Annals of Internal Medicine, 63, 27.

Pertschuk, L.P., Vuletine, J.C., Sutton, A.L. \& Velazquez, L.H. (1976) Demonstration of antigen and immune complex in glomerulonephritis due to Staphylococcus aureus. American Journal of Clinical Pathology, 66, 1027.

Peters, D.K., Martin, A., Weinstein, A., Barrat, T.M., CaMERON, J.S., OGG, C.S. \& LACHMAN, P.J. (1972) Complement studies and membranoproliferative glomerulonephritis. Clinical and Experimental Immunology, 11, 311.

SaTo, M., NAKAZORA, H. \& OFUJi, T. (1979) The pathogenetic role of staphylococcal infections in primary human glomerulonephritis. Clinical Nephrology, 11, 190.

Spector, D.A., Millan, J., Zauber, N. \& Burton, J. (1980) Glomerulonephritis and staphylococcal aureus infections. Clinica Nephrology, 14, 256.

(Accepted 24 March 1983) 